Article

\title{
Convention Tourism and Sustainability: Exploring Influencing Factors on Delegate Green Behavior That Reduce Environmental Impacts
}

\author{
Heesup Han ${ }^{1}$ [D, Soyeun Lee ${ }^{1}$, Amr Al-Ansi ${ }^{1}$, Hyeon-Cheol Kim ${ }^{2, *}$, Hyungseo Bobby Ryu ${ }^{3}$, \\ Jinkyung Jenny Kim ${ }^{4}$ and Wansoo Kim ${ }^{5}$ \\ 1 College of Hospitality and Tourism Management, Sejong University, 98 Gunja-Dong, Gwangjin-Gu, \\ Seoul 143-747, Korea \\ 2 School of Business Administration, Chung-Ang University, 84 HeukSeok-Ro, DongJak-Gu, \\ Seoul 06974, Korea \\ 3 School of Hospitality and Tourism Management, Kyungsung University, 309 Suyoungro, Nam-Gu, \\ Busan 48434, Korea \\ 4 School of Hotel and Tourism Management, Youngsan University, 142 Bansong Beltway, Haeundae-Gu, \\ Busan 48015, Korea \\ 5 Department of Tourism Management, Dong-A University, 1 Bumin-dong (2 Ga), Seo-Gu, Busan 49236, Korea \\ * Correspondence: hckim@cau.ac.kr
}

Received: 16 June 2019; Accepted: 14 July 2019; Published: 18 July 2019

check for updates

\begin{abstract}
Despite the steady growth of the convention tourism industry, little is known about the stimulation of delegates' green behaviors during their convention travel. This research sought to elucidate delegates' green behavioral intentions by taking the role of green attitudes, social norms, eco-concern, personal moral obligation, and green behaviors in daily life into account. A quantitative approach employing a survey methodology was utilized for the attainment of research goals. Our results revealed that green attitudes, social norms, eco-concern, and personal moral obligation were significant determinants of delegates' green behavioral intentions. Among these determinants, eco-concern had a salient effect on delegates' intention to practice conservation behaviors, whereas personal moral obligation had a prominent role in inducing their willingness to sacrifice. Moreover, our results uncovered that green behaviors in daily life were a moderator in maximizing the influence of green attitudes, eco-concern, and personal moral obligation on the intention to practice conservation behaviors and in maximizing the effect of social norms on the willingness to sacrifice.
\end{abstract}

Keywords: convention tourism; sustainability; delegates; green behaviors; willingness to sacrifice; environmental impacts

\section{Introduction}

Individuals' nongreen consumption behaviors are significant contributors to environmental deterioration, incessantly arousing environmental criticism [1-5]. This criticism has centered on the convention tourism sector in the global context because the industry considerably relies on various natural resources and generates a hazardous impact on the earth (e.g., air pollution from delegates' transportation use (airplane, car driving), water/soil contamination from their hotel stay, food/solid waste generation, excessive use of natural resources) [6-9]. Such environmental harms derived from the convention tourism industry have increased the concern for the environment among delegates, meeting planners, and local government officials, who highly contribute to promoting an environmentally sustainable movement in the convention tourism sector $[6,9,10]$. 
Nonetheless, despite this green movement and growing concern for the environment, surprisingly little attention has been paid to the stimulation of convention delegates' environmentally responsible behaviors. Additionally, several studies in environmental behavior and tourism sectors have indicated the significance of such factors as green attitudes, social norms, eco-concern, and personal moral obligation in explicating individuals' pro-environmental behaviors [2,4,11-14]. The criticality of these variables has also been evidenced by existing sociopsychology theories (e.g., norm activation model, value-belief-norm model, theory of planned behavior). Yet, little research has uncovered the role of the variables inducing delegates' intention to practice conservation behaviors and willingness to sacrifice during their convention travel.

Moreover, the essential role of individuals' green behaviors in daily life in explaining their consumption behaviors has been stressed by some previous consumer behavior studies [1,15-17]. However, the effect of such eco-friendly activities on everyday life has barely been integrated into the existing theoretical framework for convention delegates' decision-making processes and behavior. That is, evidence regarding the possible influence of delegates' habitual green behaviors at home/work on delegates' intention generation for pro-environmental behaviors while attending a convention has hardly been provided.

To fill these gaps, the major goal of our study was to provide insight into the elicitation of delegates' green behaviors during their convention travel. Specifically, we attempted (1) to explore the role of green attitudes, social norms, eco-concern, and personal moral obligation in generating convention delegates' green behavioral intentions (i.e., intentions to practice conservation behaviors, willingness to sacrifice); (2) expose the comparative prominence of research constructs in determining green intentions; and (3) explore the moderating impact of green behaviors in daily life on the construction of delegates' green behavioral intentions in the convention tourism sector.

\section{Literature Review}

\subsection{Environmental Deterioration and Sustainable Movement in the Convention Industry}

The convention sector, along with the entire meetings, incentives, conventions, and exhibitions (MICE) industry, is deemed an important and fast-growing tourism sector on the global stage [7,18-20]. Delegates' consumption/use of core convention-related products (e.g., meeting facilities, accommodations, catering, transportation) and their spending of money on tourism activities (e.g., dining, shopping, leisure, tours) often contribute to the economic growth of host communities $[8,21]$. However, despite this positive effect, hosting a convention and delegates' tourism activities demand an extensive amount of resources and have a substantial environmental impact on venue cities $[7,10]$. Environmental deterioration in the convention industry has thus steadily raised the concern of the public and local governments.

The environmentally responsible movement of greening a convention is unquestionably one of the top recent topics in the convention industry $[9,18]$. Indeed, practitioners in the convention industry make considerable and diverse efforts to decrease environmental deterioration and effectively implement diverse green practices $[6,8]$. The major aspect of the term "green" is minimizing harmful effects on the natural environment [18]. Such terms as green, sustainable, environmentally responsible, eco-friendly, and pro-environmental are interchangeably used [6]. Overcoming harmful impacts on the natural environment (e.g., air pollution, water contamination, soil pollution, solid waste generation, greenhouse effects) through employing and applying the "three Rs" (reduce, reuse, and recycle) is becoming one of the top priorities in today's convention industry $[6,9]$.

\subsection{Green Attitude and Its Function}

An individual's attitude toward an action is a vital facet of his/her intention formation and behavior [22-24]. As one of the volitional dimensions in an individual's decision-making process, attitude refers to "the degree to which a person has a favorable or unfavorable evaluation or appraisal 
of the behavior" [11] (p. 188). Likewise, a green attitude (in the present research) indicates the degree to which a convention delegate has a positive or negative assessment of environmentally responsible behaviors during his/her convention travel. The concept of attitude is broadly utilized as a key constituent of social psychology theories that explicate an individual's decision generation process and behavior $[11,21,23]$.

A green attitude is undoubtedly a crucial driver of diverse green intentions/activities contributing to the enhancement of the prediction power of any theoretical framework for such intentions/activities [24-26]. Indeed, many empirical studies have provided evidence that attitudes toward an eco-friendly product are positively and significantly linked to pro-environmental purchase intentions toward the product $[22,24,25,27]$. If customers hold a green attitude that is favorable for a particular green behavior, they are likely to practice it and be willing to accept possible inconveniences related to the behavior $[25,27]$.

Hypothesis 1 (H1): A green attitude positively affects the intention to practice conservation behaviors.

Hypothesis 2 (H2): A green attitude positively affects the willingness to sacrifice.

\subsection{Social Norms and Their Function}

One's social norms are regarded as an essential part of his/her self-interest/pro-social intention generation process for a particular action [11,23,28,29]. According to Ajzen [11], social norms indicate an individual's perception of social pressure regarding practicing a certain action. This social pressure is mostly derived from the importance of others' opinions about the action and from the importance of others' approval/disapproval of the action [12,22,23,30]. Thus, Steg and Vlek [30] (p. 311) described social norms as "the extent to which a behavior is supposed to be commonly approved or disapproved". In line with these descriptions, social norms, in this research, refer to a convention delegate's perception about social pressure from his/her significant others (e.g., coworkers, colleagues, family, and friends).

The concept of social norms, along with attitudes, is widely employed as a major component of sociopsychology theories explaining one's intention formation and behavior [12,23,27-29]. Many studies in the present consumer behavior literature have demonstrated that the stronger the perceived social pressure is among customers regarding practicing a specific behavior, the more they are ready and willing to perform the behavior [12,21]. The positive influence of social norms on behavioral intentions has also been demonstrated in diverse pro-environmental contexts (e.g., green product/service consumption, waste sorting/recycling, energy/water saving, public transportation use) $[22,28-31]$.

Hypothesis 3 (H3): Social norms positively affect the intention to practice conservation behaviors.

Hypothesis 4 (H4): Social norms positively affect the willingness to sacrifice.

\subsection{Eco-Concern and Its Function}

Eco-concern is broadly considered to be a critical factor in explicating the formation of environmentally friendly decisions/behaviors $[26,27,32,33]$. Eco-concern can be described as "knowing of/being concerned about the harmful influence of environmentally irresponsible human behavior on the natural environment that humans value highly" [1] (p. 1304). This variable is utilized in two different ways: [1] Concern for the specific environmental issue derived from a specific industry and [2] concern for universal environmental issues resulting from general human behavior [26,27]. This research focused on the first case, dealing with delegates' concern about the significance of environmental problems derived from the convention tourism sector. In the present study, eco-concern 
thus refers to delegates' apprehension/worry about the hazardous effects of environmentally unfriendly convention tourism behaviors on the environment.

In a growingly eco-conscious marketplace, this concept is receiving an increasing amount of attention from academics and industry practitioners in the hospitality and tourism industries [32-34]. Previous studies have indicated the important linkage between eco-concern and travelers' green intentions/behaviors $[2,35]$. These studies demonstrated the criticality of eco-concern as a significant and positive influencing factor on patrons' eco-friendly decision-making processes. Eco-concern that contains a cognitive nature is an essential precondition of patrons' eco-friendly activities [1,13,32]. Individuals with high eco-concern more readily engage in green behaviors and are willing to react to environmental issues $[2,13,32,33,35]$.

Hypothesis 5 (H5): Eco-concern positively affects the intention to practice conservation behaviors.

Hypothesis 6 (H6): Eco-concern positively affects the willingness to sacrifice.

\subsection{Personal Moral Obligation and Its Function}

Personal moral obligation is the core facet of pro-environmental/pro-social decision development $[13,14,31,36]$. This concept, which is a critical constituent of the normative dimension of pro-social human behavior [14], indicates an individual's sense of obligation to conduct himself/herself using environmentally accountable behavior $[13,37]$. Consistently, in the present research, personal moral obligation refers to delegates' internal moral obligation to perform green behaviors during their convention travel. According to Han et al. [10], this variable is pertinent to a patron's feelings of personal and ethical responsibility to take a particular action that is beneficial for society/the environment. That is, personal moral obligation is about the intrinsic aspect of the normative process [36,37].

The terms "personal moral obligation" and "moral norm" are alternatively utilized in the literature [21]. Previous studies in environmental behavior and tourism have asserted the crucial role of personal moral obligation in customers' pro-environmental decision generation processes $[10,13,31,36,38]$. The empirical evidence found in these studies has strongly supported a significant and positive linkage between personal moral obligation and eco-friendly intention. One who feels a strong sense of moral responsibility to take a pro-environmental action often behaves on the basis of a predetermined set of internal normative standards associated with what is moral and immoral [21,37]. Consistent with the indications of these studies, it is accordingly likely that travelers' intentions toward green behavior are a signification function of their personal moral obligation to conduct such actions.

Hypothesis 7 (H7): Personal moral obligation positively affects the intention to practice conservation behaviors.

Hypothesis 8 (H8): Personal moral obligation positively affects the willingness to sacrifice.

\subsection{Green Behaviors in Daily Life and Their Function}

Individuals' green behaviors in daily life can be described as their engagement in environmentally responsible activities at home and at work (e.g., water saving, energy conservation, recycling, waste reduction, avoidance of disposable product use, reuse of bath/hand/kitchen towels) [1,4,39,40]. An individual who believes in the criticality of green behaviors is likely to practice such behaviors in his/her everyday life and is ready to change his/her consumption activities to be environmentally responsible $[16,25]$. Meanwhile, a person who barely practices eco-friendly behaviors at home/work often believes that the diverse problems associated with environmental deterioration resolve themselves, and he/she barely engages in eco-friendly consumption behaviors $[15,17]$. 
Promoting patrons' green behaviors in daily life is becoming increasingly important, as habitual eco-friendly practices or activities in the real world are considered to be a trigger for green purchase/consumption behavior [1,4,16]. For instance, Han et al. [25] asserted that eco-friendly behavior in daily life is an essential variable in the consumption situation of a green hospitality product since it boosts the magnitude of the association effectiveness between patrons' green intentions/behaviors and their predictors (e.g., attitudes, social norms, perceived behavioral control). More recently, Han et al. [1] investigated the formation of patrons' intention to reuse towels while staying in a hotel. Their empirical results revealed that guests' towel reuse activity in daily life was an important contributor to increasing their towel reuse intentions at a hotel, as it strengthened the associations between this intention and its drivers (e.g., environmental concern, sense of moral obligation), acting as a critical moderator. In line with these studies, it is therefore likely that delegates' green behaviors in daily life (a moderator) influence the formation of their green behavioral intentions while attending a convention.

Hypothesis 9a-h (H9a-h): Green behaviors in daily life significantly moderate the linkages between green attitudes, social norms, eco-concern, and personal moral obligation and green behavioral intentions (the intention to practice conservation behaviors and the willingness to sacrifice).

\subsection{Proposed Conceptual Framework}

Based on the literature review described above, we proposed a theoretical model explicating the formation of convention delegates' green behavioral intentions (Figure 1). The model was comprised of green attitudes, social norms, eco-concern, and personal moral obligation as direct determinants of intentions, and it included green behaviors in daily life as a moderator. In addition, the study model was comprised of a total of nine research hypotheses. Figure 1 is the proposed model.

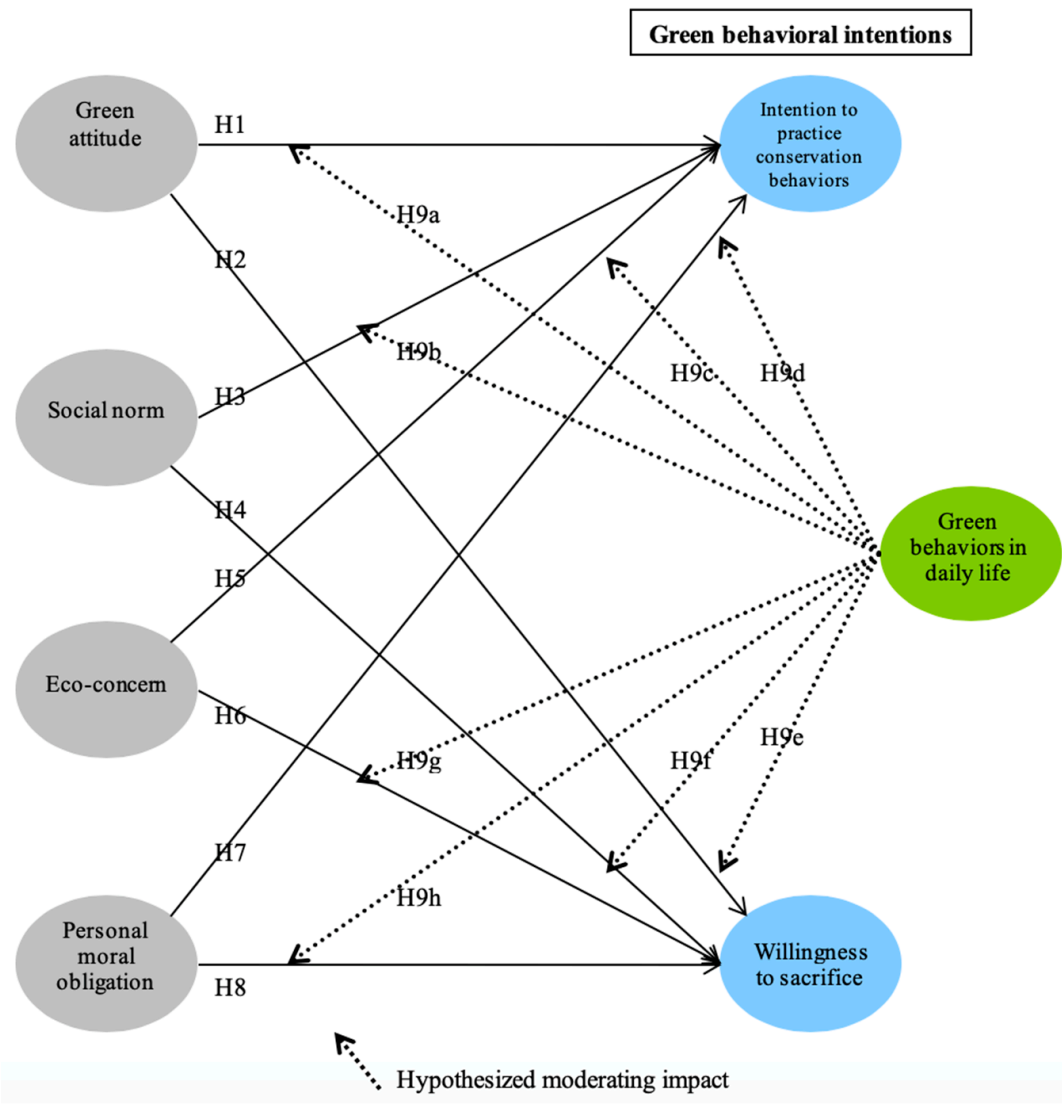

Figure 1. The proposed conceptual model. 


\section{Methods}

\subsection{Measures of the Variables and Survey Questionnaire}

To assess the study constructs, measurement items were adopted from previous environmental behavior and tourism studies [10,11,21,23,31,38,41]. In particular, three items were used for evaluations of green attitudes (e.g., "For me, engaging in green behavior while attending a convention is Bad [1]/Good [7]"). We also used three items to measure social norms (e.g., "People whose opinions I value would prefer that I engage in green behavior while attending a convention"), eco-concern (e.g., "Convention tourism can cause air pollution and global warming derived from transportation use (e.g., cars, trains, or airplanes)"), and personal moral obligation (e.g., "Regardless of what other people do, because of my own values/principles, I feel that I should act in environmentally friendly ways while attending a convention").

In addition, two items were used to assess green behaviors in daily life (e.g., "In my daily life, I often accept inconveniences in order to protect the environment (e.g., segregating waste, avoiding disposable products, decreasing solid waste, reusing towels/linens)"), intention to practice conservation activities (e.g., "The next time I attend a convention, I will try to save water and electricity"), and willingness to sacrifice (e.g., "The next time I attend a convention, I would be willing to accept inconveniences in order to protect the environment (e.g., sorting my garbage into different containers, avoiding using disposable products, decreasing waste, reusing towels/linens)"). A pretest with 12 tourism academics was conducted to measure the survey questionnaire. A slight improvement was made on the basis of their comments. Afterwards, two convention tourism experts thoroughly reviewed the questionnaire. The questionnaire was then finalized based on their feedback.

\subsection{Data Collection}

To approach valid participants and respondents, we employed an online survey methodology. The official survey invitation e-mail was sent via an online research company's system to potential participants. In a random manner, the potential respondents were selected from the database of the company. One screening question ("Have you attended any conventions within the last year?") was included in the official survey invitation e-mail. This screening question guided us toward asking specific individuals who exclusively had travel experiences for convention purposes during the past 12 months to kindly participate in the research survey. The eligible participants were requested to simply click the survey address URL link included in the survey invitation e-mail, which led them to the questionnaire page. They were asked to carefully check the research background thoroughly in the beginning of the survey and were requested to share their experiences by filling out the questionnaire. The participants spent about 9.4 min completing the survey on average. Finally, a total of 501 valid responses were received through this procedure.

\subsection{Sample Characteristics}

Of 501 respondents, about $49.7 \%$ were male convention travelers and $50.3 \%$ were female convention travelers. The participants' average age was 40.12 years old. Their ages ranged from 20 years old to 65 years old. About $26.6 \%$ reported that their age was 50 years old or more, followed by 30-39 years old $(25.3 \%), 40-49$ years old (24.6), and 29 years old or less (23.2\%). Regarding the participants' annual income, a large amount of the participants determined that their income was $\$ 25,001-\$ 55,000(44.5 \%)$, followed by $\$ 55,001-\$ 85,000(29.8 \%), \$ 25,000$ or less $(13.4 \%)$, and $\$ 85,001$ or more $(12.4 \%)$. The majority of participants reported that they were four-year college graduates $(62.5 \%)$, while $13.8 \%$ were graduate degree holders, $12.6 \%$ were two-year college graduates, and $11.2 \%$ had a high school education or less. Regarding the recency of convention travel, about $33.9 \%$ reported that their convention travel was within the last 2-3 months, followed by within the last 4-6 months (28.1\%), within the last one month (18.6\%), within the last 7-9 months (9.2\%), and within the last 10-12 months (10.2\%). All respondents' convention travel experiences were within the last one year. 


\section{Results}

\subsection{Confirmatory Factor Analysis and Validity Assessment}

AMOS 20 and SPSS 20 were used as tools for data analysis. A confirmatory factor analysis was conducted in order to estimate the measurement model. Our findings revealed that the model contained an adequate fit to the data $\left(\chi^{2}=415.095, \mathrm{df}=113, p<0.001, \chi^{2} / \mathrm{df}=3.673, \mathrm{RMSEA}=0.073, \mathrm{CFI}=0.961\right.$, $\mathrm{IFI}=0.962, \mathrm{TLI}=0.948)$. All items included significant loading values $(p<0.01)$. A composite reliability $(\mathrm{CR})$ value for each construct was calculated. The results reported that the reliability values were all higher than the thresholds of 0.700 suggested by Hair et al. [42]. The values ranged from 0.858 to 0.911 (Table 1). This result demonstrated the internal consistency of the multi-item measures. Average variance extracted (AVE) values for the research model constructs were also calculated. Our calculation revealed that all AVE values were greater than the minimum criteria of 0.500 suggested by Hair et al. [42]. Moreover, as reported in Table 1, the research model construct values were higher than the correlation values between constructs. This result provided evidence of convergent and discriminant validity.

Table 1. Results of the confirmation factor analysis and data quality testing $(n=501)$.

\begin{tabular}{|c|c|c|c|c|c|c|c|c|}
\hline Variables & (1) & (2) & (3) & (4) & (5) & (6) & (7) & CR (AVE) \\
\hline (1) Green attitudes & 1.000 & - & - & - & - & - & - & $\begin{array}{c}0.875 \\
(0.701)\end{array}$ \\
\hline (2) Social norms & $\begin{array}{c}0.507^{\mathrm{a}} \\
(0.257)^{\mathrm{b}}\end{array}$ & 1.000 & - & - & - & - & - & $\begin{array}{c}0.858 \\
(0.670)\end{array}$ \\
\hline (3) Eco-concern & $\begin{array}{c}0.508 \\
(0.258)\end{array}$ & $\begin{array}{c}0.541 \\
(0.293)\end{array}$ & 1.000 & - & - & - & - & $\begin{array}{c}0.902 \\
(0.757)\end{array}$ \\
\hline $\begin{array}{l}\text { (4) Personal moral } \\
\text { obligation }\end{array}$ & $\begin{array}{c}0.630 \\
(0.397)\end{array}$ & $\begin{array}{c}0.547 \\
(0.299)\end{array}$ & $\begin{array}{c}0.478 \\
(0.228)\end{array}$ & 1.000 & - & - & - & $\begin{array}{c}0.911 \\
(0.775)\end{array}$ \\
\hline $\begin{array}{c}\text { (5) Green behaviors in } \\
\text { daily life }\end{array}$ & $\begin{array}{c}0.566 \\
(0.320)\end{array}$ & $\begin{array}{c}0.540 \\
(0.292)\end{array}$ & $\begin{array}{c}0.798 \\
(0.637)\end{array}$ & $\begin{array}{c}0.561 \\
(0.315)\end{array}$ & 1.000 & - & - & $\begin{array}{c}0.887 \\
(0.797)\end{array}$ \\
\hline $\begin{array}{l}\text { (6) Intention to practice } \\
\text { conservation behaviors }\end{array}$ & $\begin{array}{c}0.580 \\
(0.336)\end{array}$ & $\begin{array}{c}0.519 \\
(0.269)\end{array}$ & $\begin{array}{c}0.626 \\
(0.392)\end{array}$ & $\begin{array}{c}0.626 \\
(0.392)\end{array}$ & $\begin{array}{c}0.646 \\
(0.417)\end{array}$ & 1.000 & - & $\begin{array}{c}0.894 \\
(0.809)\end{array}$ \\
\hline $\begin{array}{l}\text { (7) Willingness to } \\
\text { sacrifice }\end{array}$ & $\begin{array}{c}0.678 \\
(0.460)\end{array}$ & $\begin{array}{c}0.630 \\
(0.397)\end{array}$ & $\begin{array}{c}0.570 \\
(0.325)\end{array}$ & $\begin{array}{c}0.737 \\
(0.543)\end{array}$ & $\begin{array}{c}0.659 \\
(0.434)\end{array}$ & $\begin{array}{c}0.659 \\
(0.434)\end{array}$ & 1.000 & $\begin{array}{c}0.883 \\
(0.791)\end{array}$ \\
\hline Mean (SD) & $\begin{array}{c}4.853 \\
(1.106)\end{array}$ & $\begin{array}{c}5.415 \\
(1.019)\end{array}$ & $\begin{array}{c}5.484 \\
(1.015)\end{array}$ & $\begin{array}{c}4.763 \\
(1.199)\end{array}$ & $\begin{array}{c}5.342 \\
(1.089)\end{array}$ & $\begin{array}{c}5.256 \\
(1.108)\end{array}$ & $\begin{array}{c}5.135 \\
(1.121)\end{array}$ & \\
\hline
\end{tabular}

Note. Goodness-of-fit statistics for the measurement model: $\chi^{2}=415.095, \mathrm{df}=113, p<0.001, \chi^{2} / \mathrm{df}=3.673$, RMSEA $=0.073, \mathrm{CFI}=0.961, \mathrm{IFI}=0.962, \mathrm{TLI}=0.948$. $^{\mathrm{a}}$ Correlations between variables are below the diagonal. ${ }^{\mathrm{b}}$ Squared correlations between variables are within parentheses. CR: Composite reliability; AVE: Average variance extracted.

\subsection{Test of Structural Equation Modeling and Developed Hypotheses}

Structural equation modeling (SEM) using a maximum likelihood evaluation analytical method was performed. Our findings determined that the proposed structural model had an adequate level of goodness-of-fit statistics $\left(\chi^{2}=325.395, \mathrm{df}=89, p<0.001, \chi^{2} / \mathrm{df}=3.656, \mathrm{RMSEA}=0.073, \mathrm{CFI}=0.964\right.$, $\mathrm{IFI}=0.965$, TLI $=0.952)$. Overall, the proposed theoretical framework had an acceptable level of estimation for the intention to exercise conservation behaviors and willingness to sacrifice. In particular, about $64.9 \%$ of the variance in conservation intention and $80.8 \%$ of the variance in willingness to sacrifice was accounted for by green attitudes, social norms, eco-concern, and personal moral obligation. Details about the structural model evaluation results are reported in Figure 2 and Table 2. Figure 2 is the results model, and Table 2 is the results table. 


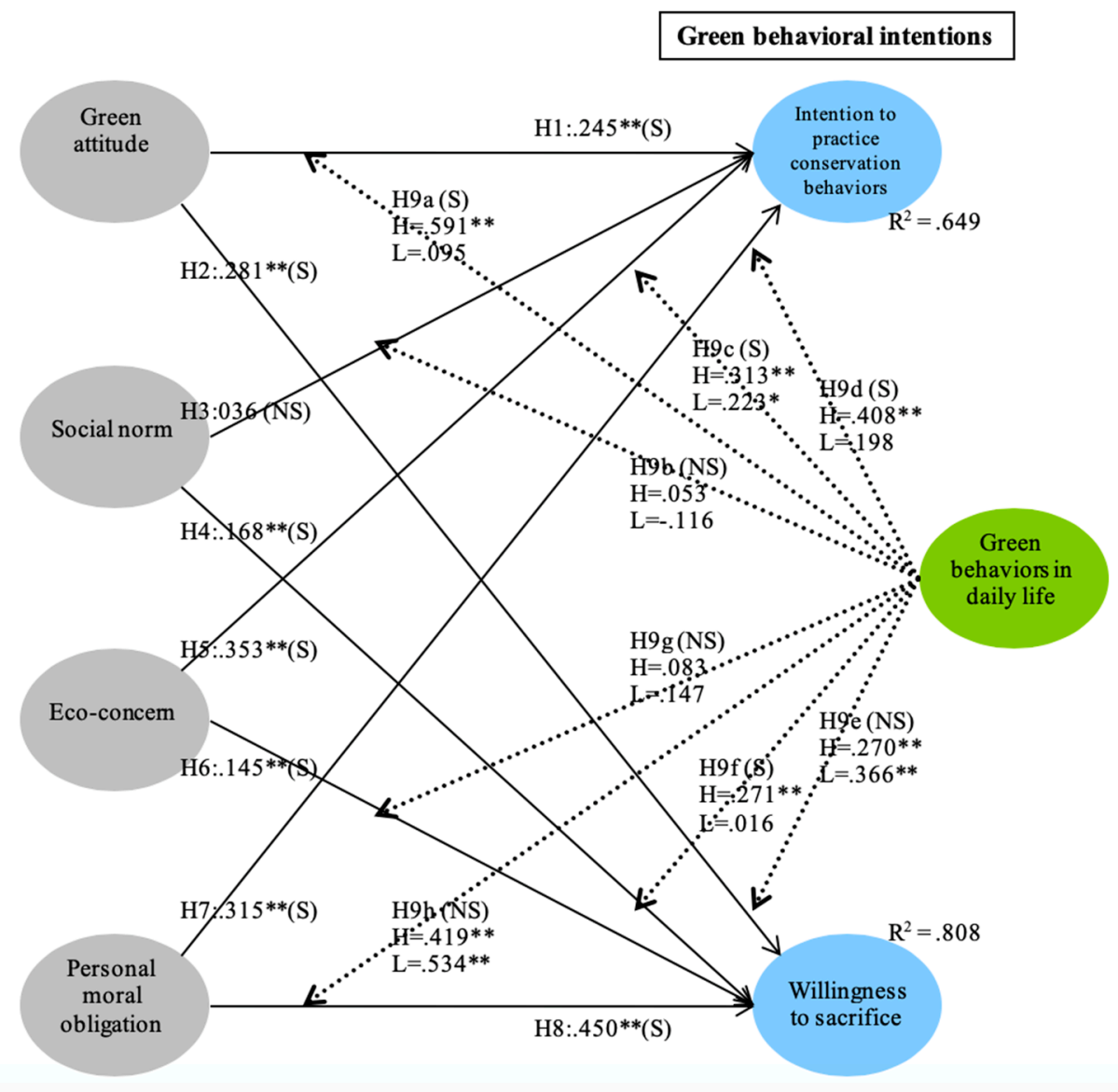

Goodness-of-fit statistics for the structural model: $\chi^{2}=325.395, d f=89, \mathrm{p}<.001, \chi^{2} / d f=3.656$, RMSEA $=.073, \mathrm{CFI}=.964, \mathrm{IFI}=.965, \mathrm{TLI}=.952$ $* \mathrm{p}<.05, * * \mathrm{p}<.01$

$\mathrm{S}=$ supported $\mathrm{NS}=$ not supported
Goodness-of-fit statistics for the baseline model: $\chi 2=465.970, \mathrm{df}=188, \mathrm{p}<.001, \chi 2 / \mathrm{df}=2.479$, $\mathrm{RMSEA}=.054, \mathrm{CFI}=.946, \mathrm{IFI}=.947, \mathrm{TLI}=.931$

$\mathrm{H}=$ high group of green behaviors in daily life

1.

Figure 2. Results of the structural model and baseline model assessment $(n=501)$.

The proposed influence of green attitudes on green behavioral intentions was examined. Our results demonstrated that green attitudes exerted a significant impact on conservation intention $(\beta=0.245$, $p<0.01)$ and willingness to sacrifice $(\beta=0.281, p<0.01)$. Thus, Hypotheses 1 and 2 were supported. The hypothesized influence of social norms was evaluated. Our results revealed that social norms were significantly connected to willingness to sacrifice $(\beta=0.168, p<0.01)$. However, social norms were not significantly linked to conservation intention $(\beta=0.036, p>0.05)$. Therefore, while Hypothesis 4 was supported, Hypothesis 3 was not supported. The proposed role of eco-concern was examined. As expected, our finding showed that eco-concern had a significant effect on conservation intention ( $\beta=0.353, p<0.01)$ and willingness to sacrifice $(\beta=0.145, p<0.01)$. Accordingly, Hypotheses 5 and 6 were supported. Finally, the impact of personal moral obligation was tested. Our results showed that personal moral obligation exerted a significant influence on conservation intention $(\beta=0.315, p<0.01)$ and willingness to sacrifice $(\beta=0.450, p<0.01)$. This finding supported Hypotheses 7 and 8 . 
Table 2. Results of the structural equation modeling $(n=501)$.

\begin{tabular}{|c|c|c|}
\hline Hypothesized Paths & Coefficients & $t$-Values \\
\hline $\begin{array}{c}\text { H1: Green attitudes } \rightarrow \text { intention to practice } \\
\text { conservation behaviors }\end{array}$ & 0.245 & $4.183^{* *}$ \\
\hline H2: Green attitudes $\rightarrow$ willingness to sacrifice & 0.281 & $5.497 * *$ \\
\hline $\begin{array}{c}\text { H3: Social norms } \rightarrow \text { intention to practice } \\
\text { conservation behaviors }\end{array}$ & 0.036 & 0.657 \\
\hline H4: Social norms $\rightarrow$ willingness to sacrifice & 0.168 & $3.565 * *$ \\
\hline $\begin{array}{l}\text { H5: Eco-concern } \rightarrow \text { intention to practice } \\
\text { conservation behaviors }\end{array}$ & 0.353 & $7.210 * *$ \\
\hline H6: Eco-concern $\rightarrow$ willingness to sacrifice & 0.145 & $3.636^{* *}$ \\
\hline $\begin{array}{l}\text { H7: Personal moral obligation } \rightarrow \text { intention to } \\
\text { practice conservation behaviors }\end{array}$ & 0.315 & $5.641 * *$ \\
\hline $\begin{array}{l}\text { H8: Personal moral obligation } \rightarrow \text { willingness } \\
\text { to sacrifice }\end{array}$ & 0.450 & $9.230 * *$ \\
\hline $\begin{array}{c}\text { Explained variance: } \\
R^{2} \text { (intention to practice conservation } \\
\text { behaviors })=0.649 \\
R^{2} \text { (willingness to sacrifice) }=0.808\end{array}$ & \multicolumn{2}{|c|}{$\begin{array}{c}\text { Goodness-of-fit statistics for the structural model: } \\
\chi^{2}=325.395, \mathrm{df}=89, p<0.001, \chi^{2} / \mathrm{df}=3.656, \mathrm{RMSEA}=0.073, \\
\mathrm{CFI}=0.964, \mathrm{IFI}=0.965, \mathrm{TLI}=0.952 \\
* p<0.05, * * p<0.01\end{array}$} \\
\hline
\end{tabular}

\subsection{Invariance Test and Baseline Model Assessment}

The hypothesized moderating impact of green behaviors in daily life was tested. All participants were separated into high and low groups of green behaviors in daily life using a $k$-means cluster analysis technique. The high group included 360 cases, whereas the low group included 141 cases. Consequently, a baseline model was generated to comprise these high and low groups. As reported in Table 3, our results demonstrated that the model had an adequate fit to the data $(\chi 2=465.970, \mathrm{df}=188$, $p<0.001, \chi 2 / \mathrm{df}=2.479, \mathrm{RMSEA}=0.054, \mathrm{CFI}=0.946, \mathrm{IFI}=0.947, \mathrm{TLI}=0.931)$. This baseline model, where all factors were equally constrained, was compared to nested models in which a specific path of interest was equally restricted. The outcomes of a chi-square test comparison were summarized in Table 3 and Figure 2.

Hypothesis $9 \mathrm{a}-\mathrm{d}$ was tested. Our findings revealed that the linkages between green attitudes $\left(\Delta \chi^{2}\right.$ $(1)=12.011, p<0.01)$, eco-concern $\left(\Delta \chi^{2}(1)=3.943, p<0.05\right)$, and personal moral obligation $\left(\Delta \chi^{2}(1)=\right.$ $3.910, p<0.05)$ and intention to practice conservation behaviors were all significantly different across the high group and low group of green behaviors in daily life. However, the linkage between social norms and conservation intention was not significantly different between the two groups $\left(\Delta \chi^{2}(1)=\right.$ $1.698, p>0.05)$. Hence, Hypothesis $9 a, c, d$ was supported. However, Hypothesis $9 b$ was not supported. Hypothesis $9 \mathrm{e}-\mathrm{h}$ was tested. Our results reported that the link between social norms and willingness to sacrifice significantly differed between the two groups $\left(\Delta \chi^{2}(1)=5.915, p<0.05\right)$. Thus, Hypothesis 9f was supported. However, the links between green attitudes $\left(\Delta \chi^{2}(1)=1.526, p>0.05\right)$, eco-concern $\left(\Delta \chi^{2}(1)=0.345, p>0.05\right)$, and personal moral obligation $\left(\Delta \chi^{2}(1)=2.823, p>0.05\right)$ and willingness to sacrifice were not significantly different across the high group and low group. Hence, Hypotheses 9e,g,h was not supported. 
Table 3. Results of the baseline model assessment and invariance test.

\begin{tabular}{|c|c|c|c|c|c|c|}
\hline \multirow[t]{2}{*}{ Paths } & \multicolumn{2}{|c|}{$\begin{array}{l}\text { High Group of Green } \\
\text { Behaviors }(n=360)\end{array}$} & \multicolumn{2}{|c|}{$\begin{array}{l}\text { Low Group of Green } \\
\text { Behaviors }(n=141)\end{array}$} & \multirow[t]{2}{*}{$\begin{array}{l}\text { Baseline Model } \\
\text { (Freely Estimated) }\end{array}$} & \multirow{2}{*}{$\begin{array}{l}\text { Nested Model } \\
\text { (Constrained) }\end{array}$} \\
\hline & $\beta$ & t-Values & $\beta$ & t-Values & & \\
\hline Green attitudes $\rightarrow$ intention to practice conservation behaviors & 0.591 & $4.878^{* *}$ & 0.095 & 1.312 & $\chi 2(188)=465.970$ & $\chi^{2}(189)=477.981^{\mathrm{a}}$ \\
\hline Social norms $\rightarrow$ intention to practice conservation behaviors & 0.053 & 0.775 & -0.116 & -1.039 & $\chi^{2}(188)=465.970$ & $\chi^{2}(189)=467.668^{b}$ \\
\hline Eco-concern $\rightarrow$ intention to practice conservation behaviors & 0.313 & $5.200 * *$ & 0.223 & $2.385 *$ & $\chi^{2}(188)=465.970$ & $\chi^{2}(189)=469.913^{c}$ \\
\hline Personal moral obligation $\rightarrow$ intention to practice conservation behaviors & 0.408 & $5.339 * *$ & 0.198 & 1.920 & $\chi^{2}(188)=465.970$ & $\chi^{2}(189)=469.880^{d}$ \\
\hline Green attitudes $\rightarrow$ willingness to sacrifice & 0.270 & $4.318^{* *}$ & 0.366 & $3.690 * *$ & $\chi^{2}(188)=465.970$ & $\chi^{2}(189)=467.496^{\mathrm{e}}$ \\
\hline Social norms $\rightarrow$ willingness to sacrifice & 0.271 & $4.558^{* *}$ & 0.016 & 0.177 & $\chi^{2}(188)=465.970$ & $\chi^{2}(189)=471.885^{\mathrm{f}}$ \\
\hline Eco-concern $\rightarrow$ willingness to sacrifice & 0.083 & 1.746 & 0.147 & 1.935 & $\chi^{2}(188)=465.970$ & $\chi^{2}(189)=466.315^{g}$ \\
\hline Personal moral obligation $\rightarrow$ willingness to sacrifice & 0.419 & $6.443^{* *}$ & 0.534 & $6.078^{* *}$ & $\chi^{2}(188)=465.970$ & $\chi^{2}(189)=468.793^{h}$ \\
\hline $\begin{array}{c}\text { Chi-square test: } \\
\text { a } \Delta \times 2(1)=12.011, p<0.01 \text { (H9a: Supported) } \\
\text { b } \Delta \times 2(1)=1.698, p>0.05 \text { (H9b: Not supported) } \\
\text { c } \Delta \times 2(1)=3.943, p<0.05 \text { (H9c: Supported) } \\
\text { d } \Delta \times 2(1)=3.910, p<0.05 \text { (H9d: Supported) } \\
\text { e } \Delta \times 2(1)=1.526, p>0.05 \text { (H9e: Not supported) } \\
\text { f } \Delta \times 2(1)=5.915, p<0.05 \text { (H9f: Supported) } \\
\text { g } \Delta \times 2(1)=0.345, p>0.05 \text { (H9g: Not supported) } \\
\text { h } \Delta \times 2(1)=2.823, p>0.05 \text { (H9h: Not supported) }\end{array}$ & \multicolumn{6}{|c|}{$\begin{array}{l}\text { Goodness-of-fit statistics for the baseline model: } \chi 2=465.970, \mathrm{df}=188, p<0.001 \\
\chi 2 / \mathrm{df}=2.479, \mathrm{RMSEA}=0.054, \mathrm{CFI}=0.946, \mathrm{IFI}=0.947, \mathrm{TLI}=0.931,{ }^{*} p<0.05,{ }^{* *} p<0.01\end{array}$} \\
\hline
\end{tabular}




\section{Discussion and Conclusions}

Sustainability/greenness is one of the most critical topics in the global convention tourism industry. This study was an empirical attempt to identify the possible influence of green attitudes, social norms, eco-concern, personal moral obligation, and green behaviors in daily life on delegates' intentions to practice conservation behaviors and willingness to sacrifice in the fast-growing convention tourism industry. The results of the structural analysis determined that green attitudes, social norms, eco-concern, and personal moral obligation were important direct contributors to increasing green behavioral intentions. While eco-concern was the key driver of intention for conservation behaviors, personal moral obligation was the foremost determinant of willingness to sacrifice. In addition, green behaviors in daily life acted as a crucial moderator in the development of delegates' green behavioral intentions. Undoubtedly, sustainability/greenness is frequently considered within competition between convention tourism venues since convention travelers are becoming more aware of the sustainable/greenness issue than ever. With a lack of empirical research about convention travelers' green behaviors, our empirical findings expressively enhance the extant body of knowledge on sustainable convention tourism.

Eco-concern was uncovered as the most critical determinant of conservation intention, whereas personal moral obligation was unearthed as the most salient factor driving willingness to sacrifice. This finding implies that delegates' concern for the environmental harms derived from the convention industry (e.g., air pollution, waste generation, water/energy/natural resource consumption) leads to their high likelihood of conservation behaviors (e.g., recycling, waste reduction, energy saving, consumption of eco-friendly goods). This finding also implies that delegates' sense of personal moral norms about green convention tourism behavior leads to their high willingness to accept inconveniences/annoyances for environmental protection (e.g., towel/linen reuse, walk/mass transit use, waste sorting, use of recycled materials).

Theoretically, this research contributes to the enhancement of knowledge regarding the comparative importance of eco-concern for conservation behaviors and the prominent role of personal moral obligation for willingness to sacrifice in the convention tourism industry. From a practical point of view, convention practitioners should make every endeavor to enhance potential/existing delegates' level of concern about convention tourism-caused environmental problems at venue destinations (e.g., global warming derived from car/train/airplane use, solid/food waste and gray water from lodging and meals, and energy/water/natural resource consumption). In addition, convention practitioners should help delegates know that acting in an environmentally friendly way during convention travel is the right thing to do and morally correct for every delegate. These efforts would increase delegates' readiness to behave in an eco-friendly manner and be willing to sacrifice while attending a convention.

The metric invariance test results of this empirical study demonstrated that the paths from green attitudes, eco-concern, and personal moral obligation to intention to practice conservation behaviors and the path from social norms to willingness to sacrifice were under significant influence from green behaviors in daily life. The strength of the relationships was significantly greater for the high group of green behaviors than for the low group. In particular, the green attitudes and conservation intention relationship was significantly stronger in the high group $(\beta=0.591, p<0.01)$ than in the low group $(\beta=0.095, p>0.05)$. The link between eco-concern and conservation intention was considerably stronger in the high group $(\beta=0.313, p<0.01)$ than in the low group $(\beta=0.223, p<0.05)$. The moral obligation and conservation intention linkage was significantly stronger in the high group $(\beta=0.408$, $p<0.01)$ than in the low group $(\beta=0.198, p>0.01)$. In addition, the social norms and willingness to sacrifice association was significantly stronger in the high group $(\beta=0.271, p<0.01)$ than in the low group $(\beta=0.016, p>0.05)$.

These empirical findings imply that at similar levels of green attitudes, eco-concern, and personal moral obligation, those delegates who often engage in green behaviors in daily life have a stronger intention to practice conservation activities during their convention travel. Our findings also imply that at similar levels of social pressure, those delegates who frequently conduct green behaviors in everyday 
life show a stronger willingness to sacrifice their conveniences. From a practical aspect, meeting planners and practitioners of host communities actively disseminate messages that green behaviors at home/work eventually bring various benefits to the natural environment and the delegates themselves.

Despite its importance, research on the effect of delegates' habitual eco-friendly behaviors at home/work on their convention tourism behaviors has scarcely been examined. Theoretically, the findings of the current study are therefore meaningful, as they provide critical evidence that green behaviors in daily life are of importance in effectively eliciting environmentally responsible tourism activities from convention travelers. Given this, the use of eco-friendly behaviors in everyday life can be imperative when developing an innovative theory/model or deepening existing conceptual frameworks for the clear explication of delegates' pro-environmental behaviors. Our empirical research demonstrated the moderation mechanism of delegates' green behaviors in daily life in the convention tourism context in a successful manner.

\section{Limitations and Future Research}

The present study entailed certain limitations that extend more opportunities for consideration in future research. First, this study mainly focused on four key constructs that adequately accounted for the total variance of delegates' green behavioral intentions. However, existing studies have indicated that there exist other important factors related to individuals' pro-environment intention generation process (e.g., anticipated guilt/pride, ascription responsibility, attachment, image) [31,38,43]. Future research could improve the prediction ability of our proposed theoretical framework by incorporating these variables. Second, the present research was specifically designed to be adequate in the convention tourism context. That is, pro-environmental decision-making procedures among patrons in other consumer behavior/tourism sectors could differ. A generalization of our research findings to other sectors therefore needs to be carefully done. Third, the subject study only considered delegate behaviors among attendees at conventions (participants). Dividing attendees into different memberships based on their roles, such as organizers or sponsors, may show different results. Such a diverse facet of concerns in convention tourism would enrich sustainable tourism going forward.

Although promoting delegates' environmentally responsible behaviors is essential in making a convention eco-friendly, convention travelers' conservation behaviors during their convention travel and willingness to sacrifice have received little attention in academic research. In addition, empirical evidence regarding what triggers such green behaviors has hardly been presented. The present research provides a better understanding of delegates' green behaviors in the convention tourism context by successfully developing a theoretical framework encompassing the influence of green attitudes, social norms, eco-concern, personal moral obligation, and green behaviors in daily life. Overall, the findings of the present study provide meaningful insights into the comparative relationships/roles of all variables in the convention tourism industry, providing practical and theoretical contributions to both convention academics and practitioners.

Author Contributions: Conceptualization, H.H.; methodology, H.H.; formal analysis, J.J.K.; investigation, W.K.; resources, H.B.R.; data curation, H.H.; writing—original draft preparation, H.H., W.K., H.-C.K. and H.B.R.; writing-review and editing, A.A.-A. and S.L.; visualization, A.A.-A. and S.L.; supervision, H.H. and W.K.; project administration, H.-C.K. and J.J.K.; funding acquisition, H.-C.K.

Funding: This work was supported by the Chung-Ang University research fund.

Conflicts of Interest: The authors declare no conflicts of interest.

\section{References}

1. Han, H.; Lee, M.J.; Kim, W. Promoting towel reuse behaviour in guests: A water conservation management and environmental policy in the hotel industry. Bus. Strategy Environ. 2018, 27, 1302-1312. [CrossRef]

2. Hwang, J.; Choi, J.K. An investigation of passengers' psychological benefits from green brands in an environmentally friendly airline context: The moderating role of gender. Sustainability 2018, 10, 80. [CrossRef] 
3. Hwang, J.; Lyu, S.O.; Cho, S.-B. In-flight casinos, Is it really a nonsensical idea? An exploratory approach using different choice experiments. Sustainability 2019, 11, 3038. [CrossRef]

4. Untaru, E.; Ispas, A.; Candrea, A.N.; Luca, M.; Epuran, G. Predictors of individuals' intention to conserve water in a lodging context: The application of an extended theory of reasoned action. Int. J. Hosp. Manag. 2016, 59, 50-59. [CrossRef]

5. Yadav, R.; Balaji, M.S.; Jebarajakirthy, C. How psychological and contextual factors contribute to travelers' propensity to choose green hotels? Int. J. Hosp. Manag. 2019, 77, 385-395. [CrossRef]

6. Lee, J.S.; Breiter, D.; Choi, Y. Quality of a Green Destination as Perceived by Convention Attendees: The Relationship between Greening and Competitiveness. Available online: http://citeseerx.ist.psu.edu/ viewdoc/download?doi=10.1.1.837.6560\&rep=rep1\&type=pdf (accessed on 5 January 2019).

7. Mair, J.; Jago, L. The development of a conceptual model of greening in the business events tourism sector. J. Sustain. Tour. 2010, 18, 77-94. [CrossRef]

8. Whitfield, J.; Dioko, L.A.N. Measuring and examining the relevance of discretionary corporate social responsibility in tourism: Some preliminary evidence from the UK conference sector. J. Travel Tour. Mark. 2012, 51, 289-302. [CrossRef]

9. Whitfield, J.; Dioko, L.A.N.; Webber, D.E. Scoring environmental credentials: A review of UK conference and meetings venues using the greener venue framework. J. Sustain. Tour. 2014, 22, 299-318. [CrossRef]

10. Han, H.; Hwang, J.; Lee, S. Cognitive, affective, normative, and moral triggers of sustainable intentions among convention-goers. J. Environ. Psychol. 2017, 51, 1-13. [CrossRef]

11. Ajzen, I. The theory of planned behavior. Organ. Behav. Hum. Dec. 1991, 50, 179-211. [CrossRef]

12. Han, H.; Yu, J.; Kim, H.; Kim, W. Impact of social/personal norms and willingness to sacrifice on young vacationers' pro-environmental intentions for waste reduction and recycling. J. Sustain. Tour. 2018, 26, 2117-2133. [CrossRef]

13. Stern, P.C. Toward a coherent theory of environmentally significant behavior. J. Soc. Issues 2000, 56, 407-424. [CrossRef]

14. Schwartz, S.H. Normative influence on altruism. In Advances in Experimental Social Psychology; Berkowitz, L., Ed.; Academic Press: New York, NY, USA, 1977; Volume 10, pp. 221-279.

15. Banerjee, B.; McKeage, K. How green is my value: Exploring the relationship between environmentalism and materialism. In Advances in Consumer Research; Allen, C.T., John, D.R., Eds.; Association for Consumer Research: Provo, UT, USA, 1994; pp. 147-152.

16. Laroche, M.; Bergeron, J.; Barbaro-Forleo, G. Targeting consumers who are willing to pay more for environmentally friendly products. J. Consum. Mark. 2001, 18, 503-520. [CrossRef]

17. Paco, A.; Rapose, M. Green segmentation: An application to the Portuguese consumer market. Mark. Intell. Plan. 2009, 27, 364-379. [CrossRef]

18. Han, H. The norm activation model and theory-broadening: Individuals' decision-making on environmentally-responsible convention attendance. J. Environ. Psychol. 2014, 40, 462-471. [CrossRef]

19. Lee, H.; Lee, J. An exploratory study of factors that exhibition organizers look for when selecting convention and exhibition centers. J. Travel Tour. Mark. 2017, 34, 1001-1017. [CrossRef]

20. Lee, H.; Lee, J.; Jones, D. Exploring the interrelationship between Convention and Visitor Bureau (CVB) and its stakeholders, and CVB performance from the perspective of stakeholders. J. Travel Tour. Mark. 2016, 33, 224-249. [CrossRef]

21. Han, H.; Hwang, J. What motivates delegates' conservation behaviors while attending a convention? J. Travel Tour. Mark. 2017, 34, 82-98. [CrossRef]

22. Matthies, E.; Selge, S.; Klöckner, C.A. The role of parental behavior for the development of behavior specific environmental norms-The example of recycling and re-use behavior. J. Environ. Psychol. 2012, 32, 277-284. [CrossRef]

23. Perugini, M.; Bagozzi, R.P. The role of desires and anticipated emotions in goal-directed behaviors: Broadening and deepening the theory of planned behavior. Brit. J. Soc. Psychol. 2001, 40, 79-98. [CrossRef]

24. Yazdanpanah, M.; Forouzani, M. Application of the theory of planned behavior to predict Iranian students' intention to purchase organic food. J. Clean. Prod. 2015, 107, 342-352. [CrossRef]

25. Han, H.; Hsu, L.; Sheu, C. Application of the theory of planned behavior to green hotel choice: Testing the effect of environmental friendly activities. Tour. Manag. 2010, 31, 325-334. [CrossRef] 
26. Zhang, Y.; Wang, Z.; Zhou, G. Determinants of employee electricity saving: The role of social benefits, personal benefits and organizational electricity saving climate. J. Clean. Prod. 2014, 66, 280-287. [CrossRef]

27. Shen, L.; Si, H.; Yu, L.; Si, H. Factors influencing young people's intention toward municipal solid waste sorting. Int. J. Environ. Res. Public Health 2019, 16, 1708. [CrossRef] [PubMed]

28. Hernández, B.; Martín, A.M.; Ruiz, C.; Hidalgo, M. The role of place identity and place attachment in breaking environmental protection laws. J. Environ. Psychol. 2010, 30, 281-288. [CrossRef]

29. Shi, H.; Fan, J.; Zhao, D. Predicting household PM2.5-reduction behavior in Chinese urban areas: An integrative model of theory of planned behavior and norm activation theory. J. Clean. Prod. 2017, 145, 64-73. [CrossRef]

30. Steg, L.; Vlek, C. Encouraging pro-environmental behaviour: An integrative review and research agenda. J. Environ. Psychol. 2009, 29, 309-317. [CrossRef]

31. Onwezen, M.C.; Antonides, G.; Bartels, J. The norm activation model: An exploration of the functions of anticipated pride and guilt in pro-environmental behavior. J. Econ. Psychol. 2013, 39, 141-153. [CrossRef]

32. Trang, H.L.T.; Lee, J.; Han, H. How do green attributes elicit pro-environmental behaviors in guests? The case of green hotels in Vietnam. J. Travel Tour. Mark. 2019, 36, 14-28. [CrossRef]

33. Wang, S.; Wang, J.; Wang, Y.; Yan, J.; Li, J. Environmental knowledge and consumers' intentions to visit green hotels: The mediating role of consumption values. J. Travel Tour. Mark. 2018, 35, 1261-1271. [CrossRef]

34. Han, H.; Lho, H.; Al-Ansi, A.; Ryu, H.; Park, J.; Kim, W. Factors triggering customer willingness to travel on environmentally responsible electric airplanes. Sustainability 2019, 11, 2035. [CrossRef]

35. Wang, P.; Liu, Q.; Qi, Y. Factors influencing sustainable consumption behaviors: A survey of the rural residents in China. J. Clean. Prod. 2014, 63, 152-165. [CrossRef]

36. Doran, R.; Larsen, S. The relative importance of social and personal norms in explaining intentions to choose eco-friendly travel options. Int. J. Tour. Res. 2016, 18, 159-166. [CrossRef]

37. Bamberg, S.; Hunecke, M.; Blobaum, A. Social context, personal norms and the use of public transportation: Two field studies. J. Econ. Psychol. 2007, 27, 190-203. [CrossRef]

38. Bamberg, S.; Schmidt, P. Incentives, morality or habit? Predicting students' car use for university routes with the models of Ajzen, Schwartz, and Triandis. Environ. Behav. 2003, 35, 264-285. [CrossRef]

39. De Roeck, K.; Farooq, O. Corporate social responsibility and ethical leadership: Investigating their interactive effect on employees' socially responsible behavior. J. Bus. Ethics 2017, 151, 923-939. [CrossRef]

40. Su, L.; Swanson, S.R. Perceived corporate social responsibility's impact on the well-being and supportive green behaviors of hotel employees: The mediating role of the employee-corporate relationship. Tour. Manag. 2019, 72, 437-450. [CrossRef]

41. Ajzen, I.; Fishbein, M. Understanding Attitude and Predicting Social Behavior; Prentice-Hall: Englewood Cliffs, NJ, USA, 1980.

42. Hair, J.F.; Black, W.C.; Babin, B.J.; Anderson, R.E. Multivariate Data Analysis, 7th ed.; Prentice-Hall: Upper Saddle River, NJ, USA, 2010; pp. 600-638.

43. Hwang, J.; Kim, S.; Choe, J.Y.; Chung, C.H. Exploration of the successful glocalization of ethnic food: A case of Korean food. Int. J. Contemp. Hosp. Manag. 2018, 30, 3656-3676. [CrossRef]

(C) 2019 by the authors. Licensee MDPI, Basel, Switzerland. This article is an open access article distributed under the terms and conditions of the Creative Commons Attribution (CC BY) license (http://creativecommons.org/licenses/by/4.0/). 